\title{
Body Design Concept of Remotely Operated Vehicle (ROV) of Observation Class with the Method of Concept Screening and Concept Scoring
}

\author{
Dhimas Satria, ${ }^{1, *}$,Dovan Pujangga Asmara Lanank Esiswitoyo ${ }^{1}$, Ni Ketut Caturwati ${ }^{1}$, \\ Erny Listijorini ${ }^{1}$, Rina Lusiani ${ }^{1}$ \\ ${ }^{1}$ Mechanical Engineering Department, Universitas Sultan Ageng Tirtayasa, Indonesia
}

\begin{abstract}
The Remotely Operated Vehicle (ROV) underwater observation equipment has previously been developed, but it had restriction for not being hydrodynamic still due to the unique conditions of the Sunda Strait waters. This study aims to further develop the previously developed ROV by improving the design structure of the ROV body. The method of design concept selection used was concept screening and concept scoring. In concept screening, the initial concept was evaluated relatively to the same preferences using screening matrices. On the other hand the Concept Scoring was conducted by determining the relative performance value which was the assessment used to evaluate how the comparison between concepts and number as the comparison. The result of the study obtained the selected design concept, which was small ROV with streamlined / half-streamlined body geometry which had rear-middle rotor configuration as motion component of hydrodynamic 3 DOF (surge, heave, and yaw).
\end{abstract}

\section{Introduction}

ROV design which is previously developed has limitation in design structure and hydrodynamic response [1]. The solution of those problems is the development of correct design structure suitable for hydrodynamic [2][3], and also has current design. Geometry and the body shape of moving object in flowing fluid affect hydrodynamic respond design, which is ROV body design structure [4][5][6]. The geometry of equipment working in moving fluid is determined by the parametric geometry [7]. Meanwhile the shape of body is determined by design optimization with form follow function method which refer to parametric geometry [8].

Design optimization is started with the concept formulation. Two concept selection needs to be through to obtain the concept; those are concept screening and concept scoring. Therefore this study aims to obtain ROV body design concept structure is in accordance with the criterion of hydrodynamic used as the basis the development of design ROV of

\footnotetext{
*Corresponding author: dhimas@untirta.ac.id
} 
observation class [9]. The second part gives method of concept selection, in which product specification developed into solution and concept alternatives. Meanwhile the third part is the result obtained after concept selection step.

\section{Method}

The method of concept selection used is a method that has been widely used in design planning that is Pahl \& Beitz method [10]. Pahl \& Beitz stated that design is a process of creativity but is limited by the provisions that have been established to produce design through creativity. Fig. 1 illustrate Pahl \& Beitz method is a conceptualization method that is composed from the process of translating the specifications and needs of prospective users into the technical language, to form the concept of design of the results of elimination and assessment concept against the criteria.

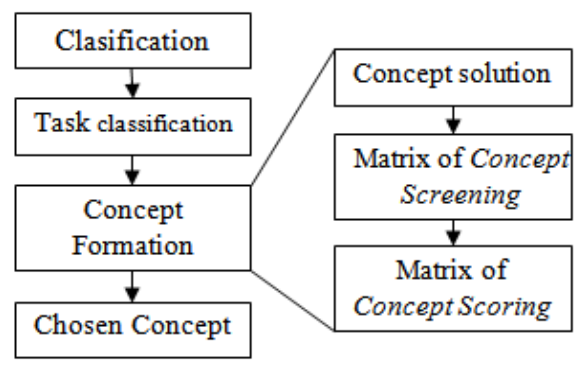

Fig. 1. Conceptualization Step of Pahl \& Beitz Method. [10]

Specifications and the needs of potential users are obtained by collecting qualitative data expected by prospective users. Qualitative data were obtained by interviewing prospective users and document studies of the literature collected from various sources. Qualitative data are collected in the product specification sheet and reviewed together with quantitative data from the previous design structure specifications. Quantitative data processing is classified according to the task to be qualified by the ROV, which contains; structure, mobility, operating conditions, operating time, effectiveness, and interaction.

Data specifications and user requirements compiled in the specification sheet are reviewed by identifying the subject matter. Identification is conducted by abstraction and problem formulation through five steps of the abstraction process [10]. The five steps of the abstraction process produce the formulation of the problem; geometry and/or vehicle design with operating conditions determined by hydrodynamic response, with variations in speed and acceleration, and degrees of freedom.

\section{Result}

The product specifications which have been identified in the permeate formulation determine the main functions that describe the relationship between incoming and outgoing data values (outcomes). The problem formulation forms the overall design function in the block diagram. 


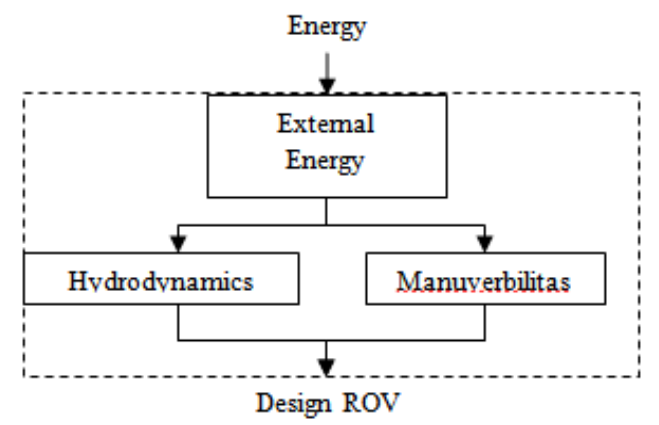

Fig. 2. Block Diagram Sub function.

Fig. 2 illustrates block diagrams composed of sub-functions that influence concept formation. Fig. 3 illustrates each sub-function that is the definition of the problem requires a solution. Possible solutions for Hydrodynamics sub-functions are; ROV size and ROV geometry, and solutions for manuverbility sub-functions are; driver configuration and motion system model.

Based on literature [10][11], the selection of concepts consists of two stages. The first stage is the concept screening and the second stage is the concept of scoring. In concept screening, solutions are evaluated relative to references using screening matrices. At this stage the quantitative comparison evaluation uses values relative to the criteria. Once the solution is evaluated, each solution is formed in an alternative concept that may be formed. Alternative concepts are evaluated by concept scoring using scoring matrix.

Fig. 3. Solution Sub-function.

\begin{tabular}{|l|l|}
\hline Hydrodinamic & \multicolumn{1}{|l|}{$\begin{array}{l}\text { Manuverbilitas } \\
\text { Size }\end{array}$} \\
Big & Configuration \\
Medium & Front-Back \\
Small & Middle \\
& Middle-Back \\
Geometry & Back \\
Sphere/half & Degree of freedom \\
Cone/cube & 1 DOF \\
Angled cube & 3 DOF \\
Long cylinder & 3 DOF DP \\
Streamlined/half & 4 DOF \\
& 6 DOF \\
\hline
\end{tabular}

\subsection{Concept Screening}

In this study, the concept screening method used is a method developed by Stuart Pugh in 1980 known as Pugh Concept Selection. Table 1 is the concept screening matrix. Selection criteria are criteria formed from problem formulations and specification sheets. Each solution in its sub-functions is given an assessment of the selection criteria by taking one of each solution in the sub-function as an assessment reference. Sub-functional solutions that most likely meet the selection criteria are given a positive $(+)$ value, while those with a small chance of meeting selection criteria against reference are assigned as a negative (-). The assessment has a weight of 1 for a positive value (+), 0 for an assessment that has the same criteria as the reference, and -1 for the negative (-). The weights obtained from the solution are summed to form a ranking. 
Table 1. Concept screening matrix.

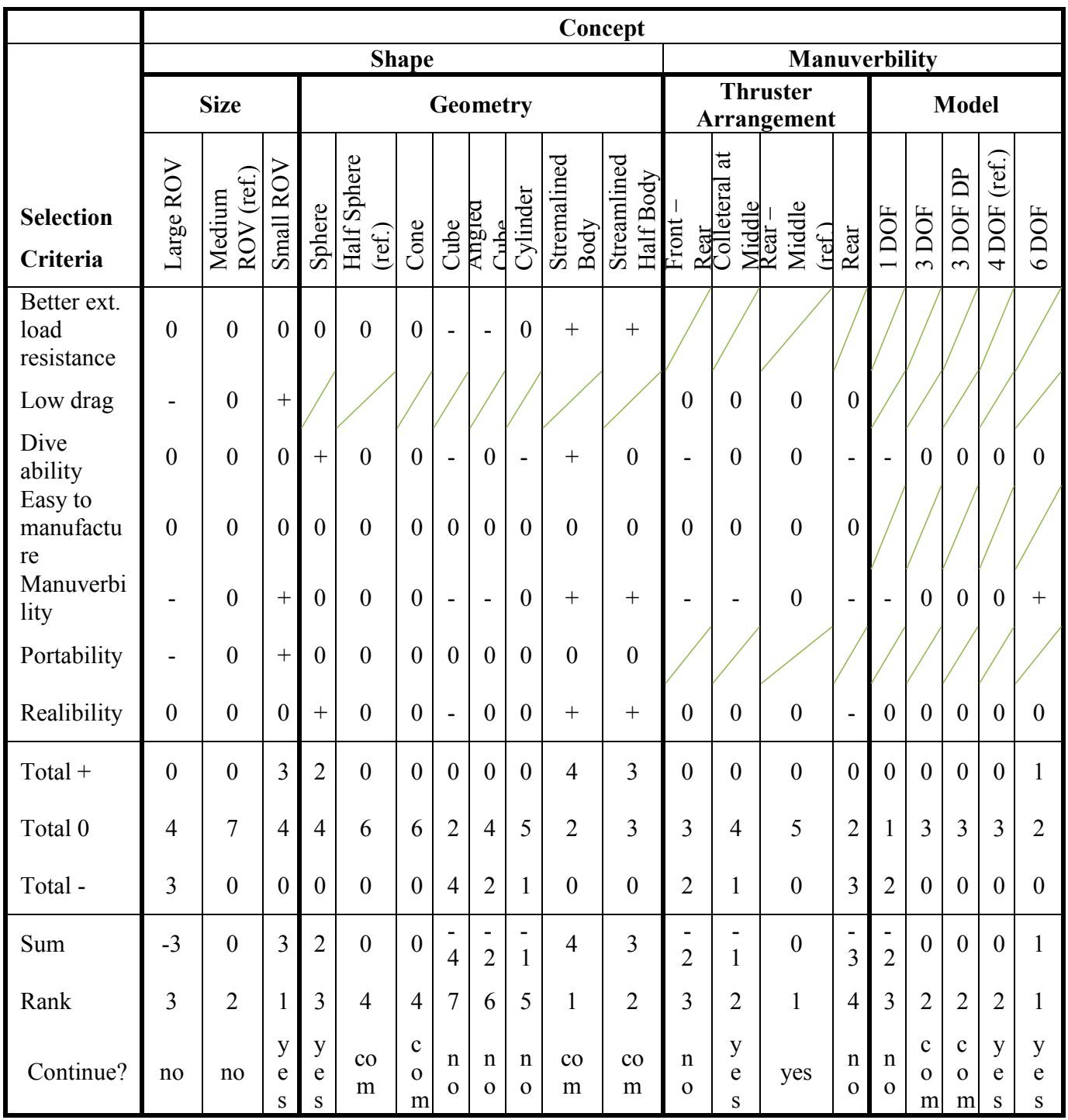

The concept screening process gets the solution that has the greatest possibility of being a concept. The solution used for the process of forming alternative concepts is indicated by the words yes and comb, which means the solution needs to be combined to meet the selection criteria, in the section that indicates "continue?". However, one solution is that the model has been determined by potential users.

\subsection{Concept Scoring}

An alternative concept variant is formed from a solution that has been evaluated. The concept variant connects each solution into a unified concept of alternative sub-functions. The concept variant comprising one connected solution of each sub-functions, given the symbol of Variant $\mathrm{x}, \mathrm{x}=\mathrm{A}, \mathrm{B}, \mathrm{C}, \ldots . ., \mathrm{N}$. Table 2 is score relative performance. 
Table 2. Score relative performance.

\begin{tabular}{|c|c|}
\hline Relative Performance & score \\
\hline Worse than reference & 1 \\
\hline Slightly worse than reference & 2 \\
\hline Same as reference & 3 \\
\hline Slightly better than reference & 4 \\
\hline Worse than reference & 5 \\
\hline
\end{tabular}

Table 3. Solution sub-function.

\begin{tabular}{|c|c|c|c|c|c|c|c|c|c|c|c|c|c|c|c|c|c|c|c|}
\hline $\mathbf{R}$ & $\mathbf{Q}$ & $\mathbf{P}$ & $\mathbf{O}$ & $\mathbf{N}$ & $\mathbf{M}$ & $\mathbf{L}$ & $\mathbf{K}$ & $\mathbf{J}$ & $\mathbf{I}$ & $\mathbf{H}$ & $\mathbf{G}$ & $\mathbf{F}$ & $\mathbf{E}$ & D & $\mathbf{C}$ & B & $\mathbf{A}$ & \multicolumn{2}{|l|}{ Concept } \\
\hline \multicolumn{18}{|c|}{ Small ROV } & $0 \quad n-m$ & \\
\hline \multicolumn{6}{|c|}{$\begin{array}{l}\text { Streamlined Body/Half } \\
\text { Streamlined Body }\end{array}$} & \multicolumn{6}{|c|}{ Half Sphere/Cone } & \multicolumn{6}{|c|}{ Sphere } & 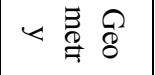 & \\
\hline \multicolumn{3}{|c|}{$\begin{array}{l}\text { Rear- } \\
\text { Middle }\end{array}$} & \multicolumn{3}{|c|}{$\begin{array}{l}\text { Colleteral at } \\
\text { Middle }\end{array}$} & \multicolumn{3}{|c|}{$\begin{array}{l}\text { Rear- } \\
\text { Middle }\end{array}$} & \multicolumn{3}{|c|}{$\begin{array}{l}\text { Colleteral at } \\
\text { Middle }\end{array}$} & \multicolumn{3}{|c|}{$\begin{array}{l}\text { Rear-- } \\
\text { Middle }\end{array}$} & \multicolumn{3}{|c|}{$\begin{array}{l}\text { Colleteral at } \\
\text { Middle }\end{array}$} & 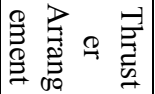 & $\vec{\circ}$ \\
\hline 6 & 4 & 3 & 6 & 4 & 3 & 6 & 4 & 3 & 6 & 4 & 3 & 6 & 4 & 3 & 6 & 4 & 3 & $\begin{array}{llll}3 & \theta & 0 & 0 \\
0 & 0 & 0 \\
2\end{array}$ & \\
\hline
\end{tabular}

The concept screening stage uses the number of value distribution of each concept. Assessment of concept scoring uses the Karl method [11], where the karl method uses a relative performance value of 1 to 5 (Table 3 ). Relative performance values are assessments used to evaluate how the comparison of concepts to references by using the score significance as a comparison.

Concept Variants formed is evaluate by comparing the selection criteria. Selection criteria are judged by the weight of each criterion from the highest to the lowest in scale of 100. As in the prior conception process, concept screening, in the conception process of concept scoring it is necessary to define conceptual reference, where one of the references has been specified in the table. In the concept scoring table each concept is assessed against the selection criteria of relative performance value, which is the value of the ratio (rating) of the concept. For the final assessment, the value of the ratio and the weight of the criteria are multiplied and summed in one concept resulting in the total value that is the rank of each concept. The concept that has the greatest total value of reference is the chosen concept that will be further developed for analysis.

$$
S_{J}=\sum_{i=1}^{n} r_{i j} w_{i}
$$

whence

$$
\begin{aligned}
& r_{i j}=\text { score of raw concept }{ }^{j} \text { for }{ }^{i} \text { criterion } \\
& w_{i}=\text { score for }{ }^{i} \text { criterion } \\
& n \quad=\text { number of criterion }
\end{aligned}
$$


The concept has been selected through the concept screening stage and concept scoring. Both stages eliminate alternative concepts that have no score better than the chosen concept. Selected concept to be tested (concept testing) with simulation method, that is:

The concept of P small ROV with streamlined / half-streamlined body geometry which has a rear-middle rotor configuration as a motion component of hydrodynamic 3 DOF (surge, heave, and yaw) models.

\section{Conclusion}

The result of the research got the selected design concept, that is small ROV with streamlined / half-streamlined body geometry which has rear-middle rotor configuration as motion component of hydrodynamic 3 DOF (surge, heave, and yaw).

\section{Acknowledgments}

The authors would like to send the gratitude to the Directorate of Research and Community Service (DRPM) of DIKTI who has funded this research in the 2018.

\section{References}

1. R. Wiryadinata, A. S. Nurliany, I. Muttakin, and T. Firmansyah, Design of a Low Cost Remotely Operated Vehicle with 3 DoF Navigation, Bull. Electr. Eng. Informatics, vol. 6, no. 1, pp. 13-23 (2017)

2. K. Amjith, V. Arundas, M. Harikrishnan, J. Sebastian, and V. Vineeth, Underwater Search and Rescue Device, Int. J. Innov. Res. Sci. Technol., vol. 1, no. 11, pp. 481-488 (2015)

3. D. L. Paster, Importance of Hydrodynamic Considerations for Underwater Vehicle Design, IEEE, pp. 1413-1422 (1986)

4. F. Aguirre, State of the Art of Parameters for Mechanical Design of an Autonomous Underwater Vehicle, Int. J. Ocean. Oceanogr., vol. 11, pp. 89-113 (2017)

5. H. G. Park, Hydrodynamic Design of an Underwater Hull Cleaning Robot and Its Evaluation, Int. J. Nav. Archit. Ocean Eng., vol. 4, pp. 332-352 (2012)

6. R. D. Christ, The ROV Manual. Oxford: Elsevier (2007)

7. P. S. Granville, Geometrical Characteristic of Streamlined Shapes. Washington D.C: Department of the Navy Naval Ship Research and Development Center (1969)

8. H. . Nguyen, Design, Modelling, and Simulation of a Remotely Operated Vehicle, $J$. Comput. Sci. Cybern., vol. 29, pp. 299-312 (2013)

9. W. Chuanfeng, Z. Fumin, and D. Schaefer, Dynamic modeling of an autonomous underwater vehicle, J. Mar. Sci. Technol., no. August (2015)

10. G. Pahl and W. Beitz, Engineering Design: A Systematic Approach, Second Edi. London: Springer-Verlag (1996)

11. K. T. Ulrich and S. D. Eppinger, Product Design and Development, 6th Editio. New York: McGraw-Hill, Inc (2016) 